\title{
Disparity in Discolouration of Thermally Modified Wood Exposed to Solar and Artificial Ultraviolet Irradiation
}

\author{
Dace Cirule*, Edgars Kuka, Andis Antons \\ Latvian State Institute of Wood Chemistry, Dzērbenes str.27, Rīga, LV-1006, Latvia \\ Latvia University of Agriculture, Lielā str. 2, Jelgava, LV-3001, Latvia
}

\begin{abstract}
Artificial weathering is a widely used method for predicting wood behaviour during its service life. A study was carried out to compare the colour change of thermally modified aspen (Populus tremula L.) and grey alder (Alnus incana (L.) Moench) wood during natural solar and artificial ultra violet (UV) irradiation. Thermally modified wood specimens were exposed for $30 \mathrm{~h}$ to artificial UV irradiation at two different intensities, i.e. $1.36 \mathrm{~W} \mathrm{~m}^{-2}$ at $340 \mathrm{~nm}$ and $0.68 \mathrm{~W} \mathrm{~m}^{-2}$ at $340 \mathrm{~nm}$, as well as to solar irradiation outdoors and indoors. After 2.5, 5 and $10 \mathrm{~h}$ exposure, colour parameters and reflectance spectra (360-740 nm) were determined. Colour was expressed in accordance with the CIELAB colour model as colour parameters $\mathrm{L}^{*}, \mathrm{a}^{*}, \mathrm{~b}^{*}$. The total colour change $\Delta$ Eab was calculated from colour parameter differences $\Delta \mathrm{L}^{*}, \Delta \mathrm{a}^{*}, \Delta \mathrm{b}^{*}$. The colour changes caused by solar and artificial UV irradiation had a similar pattern for both thermally modified hardwood species under study. Changes in the individual colour parameters in the course of the experiment altered their direction, which implies that discolouration of thermally modified wood is a complicated and dynamic process with various and different chemical transformations in wood chromophores. Colour and reflectance changes had similar trends for different intensities of the same type of irradiation, but they differed for various irradiation types - natural solar or artificial UV irradiation. Greater discolouration was detected for the specimens exposed to both solar irradiations - outdoors and indoors. The results suggest that the fluorescent lamps of the UVA340 type, which only imitate well the sunlight UV spectrum from $290 \mathrm{~nm}$ to $365 \mathrm{~nm}$, do not fully simulate the changes in thermally modified wood induced by solar radiation.
\end{abstract}

Keywords: Thermally modified wood, Discolouration, Solar irradiation, Artificial UV irradiation.

\section{Introduction}

Thermal modification is known as an effective method to improve some properties of wood such as dimensional stability, resistance against biodegradation and decrease of hygroscopicity (Esteves \& Pereira, 2009). Unfortunately, wood mechanical strength decreases due to thermal treatment (Boonstra et al., 2007). Therefore, major application fields of thermally modified wood are, for example, garden furniture, decking, spa areas, swimming pools and floorings (Bächle et al., 2010). When wood is exposed outdoors, a complex combination of chemical and mechanical factors contributes to what is described as weathering, i.e. a complex set of reactions induced by solar radiation, water (rain, dew, snow and humidity), temperature and atmospheric pollution (sulphur dioxide, nitrogen dioxide, ozone, dust, etc.) (Williams, 2005). UV light is known to be the main reason for degradation and discolouration of wood surface during weathering (Ayadi et al., 2003). Artificial weathering is extensively used to predict the behaviour of wood outdoors as the process is controllable and reproducible. Another advantage of artificial weathering is that results can be obtained in a relatively short time. A lot of information about the artificial weathering of unmodified (Derbyshire \& Miller, 1981; Oltean, Teischinger, \& Hansmann, 2008; Pandey \& Vuorinen, 2008; Tolvaj \& Varga, 2012) as well as thermally modified wood (Ayadi et al., 2003; Deka et al., 2008; Miklečić et al., 2011; Huang et al., 2012) is available. Different types of light sources are applied to simulate solar radiation. Mostly xenon arc (Tolvaj \& Mitsui, 2005; Srinivas \& Pandey, 2012) and fluorescent (Chang et al., 2010; Miklečić et al., 2011) lamps are used.

Light provokes chemical reactions on wood surface. As wood discolours as a result of these reactions, it is easy to monitor the weathering process through determining wood colour changes (Ayadi et al. 2003; Kishino \& Nakano 2004; Pastore et al. 2004; Temiz et al. 2005; Mitsui 2006; Sharratt et al. 2009). The UVA type fluorescent lamps are widely used in the case of the artificial weathering of thermally modified wood. There are some studies about unmodified wood in which the changes in wood during exposure to artificial UV irradiation and solar irradiation outdoors are compared (Derbyshire \& Miller 1981; Sudiyani et al. 1999; Tolvaj \& Mitsui, 2005; Deka \& Petric 2008). Unfortunately, there is hardly any knowledge about peculiarities of thermally

\footnotetext{
* Corresponding Author's email: xylon@edi.lv
} 
modified wood discolouration caused by artificial and natural solar irradiation. However, the information on how well the artificial weathering is able to imitate natural processes is an important issue concerning investigation and prediction of material behaviour during its application.

The objective of the present study was to evaluate how well artificial weathering by using fluorescent lamps of the UVA-340 type is able to imitate the changes in thermally modified wood colour during exposure to solar radiation.

\section{Materials and Methods \\ Wood specimens}

Two common Latvian hardwood species, i.e. aspen and grey alder were used for the study. Aspen and grey alder boards measuring 1000 x $100 \times 40 \mathrm{~mm}$ were hydrothermally modified in an experimental wood modification device in a water vapour medium for $1 \mathrm{~h}$ at $170{ }^{\circ} \mathrm{C}$ under elevated pressure $(0.8$ $\mathrm{MPa}$ ). Before preparing specimens for weathering experiments, the boards were conditioned at $20{ }^{\circ} \mathrm{C}$ and $65 \% \mathrm{RH}$ until the equilibrium moisture content was reached. Specimens measuring 150 × 70 x 15 $\mathrm{mm}$ were cut from the conditioned boards to be further used for the artificial UV irradiation at two intensities and for exposure to sunlight outdoors and indoors. For each experiment, three specimens from each species were prepared.

Solar irradiation tests

One set of specimens was exposed to solar irradiation on a horizontal surface outdoors. This test was labelled as "Outdoor". Another set was placed on a horizontal surface indoors in a place where specimens were subjected to sunlight filtered through the window glass. This test was labelled as "Indoor". The experiment site was located in Riga $-56^{\circ} 58^{\prime} \mathrm{N}$, $24^{\circ} 11^{\prime} \mathrm{E}$. During the experiment, the air temperature at the surface of the specimens varied from 20 to $28{ }^{\circ} \mathrm{C}$ and relative humidity from 20 to $43 \%$. The total exposure time was $30 \mathrm{~h}$. After $2.5,5$ and $10 \mathrm{~h}$ exposure, colour parameters and reflectance spectra of the specimens were recorded. Every hour outdoors and indoors, the total ultraviolet (UV) radiation flux density in a range of 290-390 nm was measured using an UV light meter. The irradiation doses received by specimens were calculated from these data. The experiment was carried out from June to August and the specimens were only exposed to irradiation during the hours when the UV radiation flux density outdoors was not less than $10 \mathrm{~W} \mathrm{~m}^{-2}$. Wood was kept in the dark in the laboratory while it was not exposed to irradiation.

\section{Artificial UV irradiation tests}

Artificial UV irradiation was performed in an accelerated weathering tester QUV equipped with fluorescent lamps of UVA-340 type, which are commonly used in artificial weathering and provide good simulation of sunlight in the short wavelength region from $365 \mathrm{~nm}$ to the solar cut-off of $295 \mathrm{~nm}$ with a peak emission at $340 \mathrm{~nm}$.

The artificial UV irradiation was carried out in two modes, which differed in irradiation intensities. In a test labelled "Intense", the UV radiation flux density at $340 \mathrm{~nm}$ was $1.36 \mathrm{~W} \mathrm{~m}^{-2}$ and in a test labelled "Mild", it was $0.68 \mathrm{~W} \mathrm{~m}^{-2}$. The total UV radiation flux densities in a range of 290 to $390 \mathrm{~nm}$ were $30.5 \mathrm{~W} \mathrm{~m}^{-2}$ in the Intense test and $17.5 \mathrm{~W} \mathrm{~m}^{-2}$ in the Mild test. During both artificial weathering tests the temperature in the weathering chamber was $60^{\circ} \mathrm{C}$. Total exposure time was $30 \mathrm{~h}$. Tests were suspended after $2.5,5$ and $10 \mathrm{~h}$ to perform spectrophotometric measurements.

\section{Spectrophotometric measurements}

Reflectance spectra and wood colour was measured with a spectrophotometer CM-2500d (standard illuminant D65, d/8 ${ }^{\circ}$ measuring geometry, $10^{\circ}$ standard observer, measuring area $\varnothing 8 \mathrm{~mm}$ ) before and after irradiation as well as after 2.5, 5 and $10 \mathrm{~h}$ exposure. Colour was expressed in accordance with three dimensional colour space CIELAB where parameter $\mathrm{L}^{*}$ indicates the lightness in a range from black (0) to white $(100)$, while parameters $a^{*}$ and $b^{*}$ define the position in green-red and blue-yellow axis respectively. The total colour change $\Delta \mathrm{Eab}$ is a distance between two points in the colour space and was calculated from the colour parameter differences between the initial and resulting values $\Delta \mathrm{L}^{*}, \Delta \mathrm{a}^{*}$, $\Delta \mathrm{b} *$ (e.g. $\Delta \mathrm{L}^{*}=\mathrm{L}^{*}{ }_{\text {resulting }}-\mathrm{L} *$ initial) according to the formula:

$$
\Delta \mathrm{E} a b=\left(\left(\Delta L^{*}\right)^{2}+\left(\Delta a^{*}\right)^{2}+\left(\Delta b^{*}\right)^{2}\right)^{\frac{1}{2}}
$$

Reflectance spectra were recorded in a range of 360-740 nm, measuring the reflectance at $10 \mathrm{~nm}$ intervals. Colour parameters and reflectance spectra were measured at five, always the same positions on each specimen and average values were calculated.

\section{Results}

Variation of the UV radiation flux density in a range of 290-390 $\mathrm{nm}$ for all tests of this study is shown in Figure 1. The UV radiation in both artificial weathering tests was constant during the whole experiment. UV radiation intensity in both solar radiation tests varied from day to day as well as it varied from hour to hour depending on the time of day. 


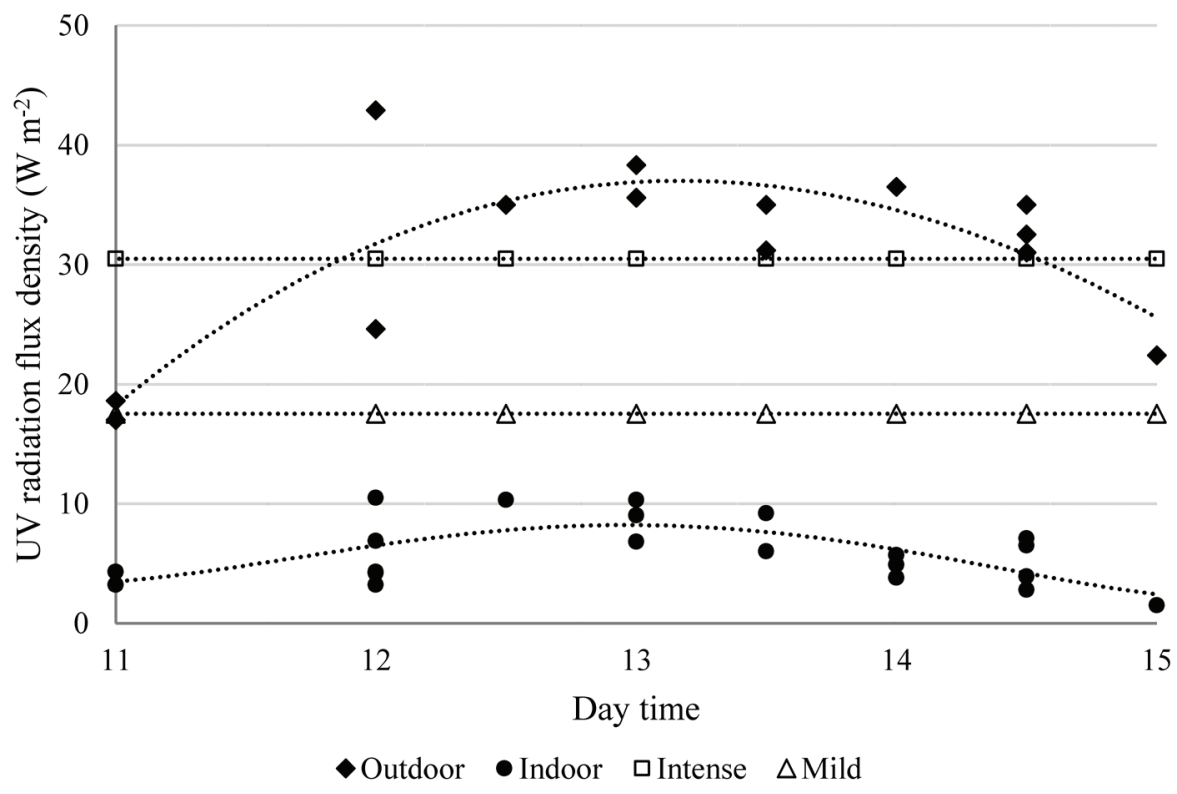

Figure 1. Variation of the UV radiation flux density in a range of $290-390 \mathrm{~nm}$ during Outdoor, Indoor, Intense, and Mild tests.

During the experiment, the highest radiation in the UV range in both solar tests was detected between 12 $\mathrm{pm}$ to $14 \mathrm{pm}$. As the UV intensity varied during solar irradiation tests, the UV irradiation doses received by the specimens during exposure were calculated (Table 1).

The highest total UV irradiation dose in a wavelength range of 290-390 nm, received by the specimens during $30 \mathrm{~h}$ of exposure was for the specimens artificially irradiated in the Intense test $-3300 \mathrm{~kJ} \mathrm{~m}^{-2}$. Much lower and almost equal UV irradiation doses during $30 \mathrm{~h}$ exposure received specimens in the Outdoor and Mild tests $-2000 \mathrm{~kJ} \mathrm{~m}^{-2}$ and $1900 \mathrm{~kJ} \mathrm{~m}^{-2}$, respectively, whereas the specimens exposed to solar irradiation through the window glass in the Indoor test were only reached by $24 \%$ of that of the full solar UV radiation in the Outdoor test.

At the end of the experiment, considerable colour changes $\Delta \mathrm{Eab}$ were detected for all studied irradiation conditions for both wood species (Figure 2 ). However, less discolouration was observed for specimens subjected to exclusively UV irradiation in both artificial weathering tests despite the substantial UV radiation dosages received by the specimens in these tests.

Thermally modified wood exposed to solar and artificial UV irradiation differed not only by the magnitude of total discolouration, but also by changes in individual colour parameters (Table 2). However, the pattern of colour change was similar for both thermally modified aspen and grey alder wood.

In both solar irradiation tests from the very beginning the lightness $\mathrm{L}^{*}$ of both species increased $\left(\Delta \mathrm{L}^{*}>0\right)$, which means that wood became lighter. Unlike, in both artificial UV irradiation tests at the initial stage of the exposure darkening of wood was

Table 1

UV irradiation $(290-390 \mathrm{~nm})$ doses received by specimens during solar and artificial UV exposure for different periods of time

\begin{tabular}{ccccc}
\hline \multirow{2}{*}{$\begin{array}{c}\text { Exposure } \\
\text { time, } \mathbf{h}\end{array}$} & \multicolumn{4}{c}{ Irradiation doses, $\mathbf{k J} \mathbf{~ m}^{\mathbf{2}}$} \\
\cline { 2 - 5 } & Outdoor & Indoor & Intense & Mild \\
\hline 2.5 & 250 & 60 & 270 & 160 \\
\hline 5 & 450 & 110 & 550 & 320 \\
\hline 10 & 960 & 230 & 1100 & 630 \\
\hline 30 & 2000 & 470 & 3300 & 1900 \\
\hline
\end{tabular}




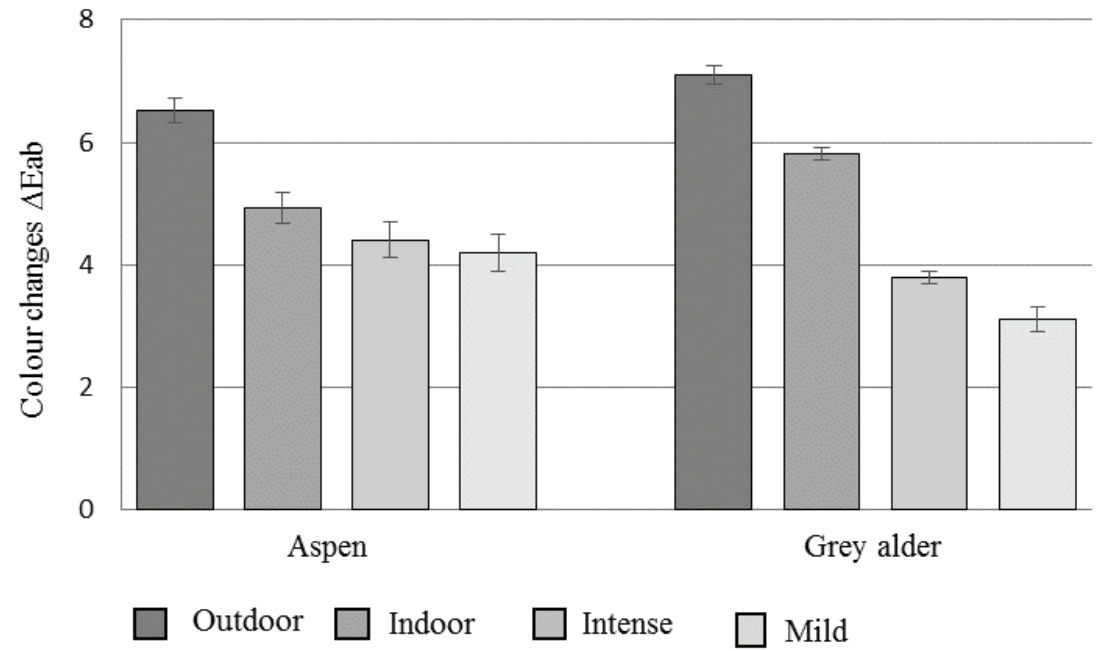

Figure 2. Colour change $\Delta \mathrm{Eab}$ of thermally modified aspen and grey alder wood during exposure to different irradiation conditions for $30 \mathrm{~h}$.

detected $\left(\Delta \mathrm{L}^{*}<0\right)$, which was followed by increase in lightness during the further exposure. For the specimens exposed in the Intense test, positive lightness change values $\Delta \mathrm{L}^{*}$ were fixed after $5 \mathrm{~h}$ irradiation while for those in the Mild test after $10 \mathrm{~h}$ of exposure.
The redness parameter $\mathrm{a}^{*}$ declined $\left(\Delta \mathrm{a}^{*}<0\right)$ during the whole experiment for specimens exposed to all weathering conditions. Slightly greater changes in redness at the end of the experiment were found for specimens subjected to the artificial UV irradiation. However, the most distinctive behaviour in solar

Table 2

Changes in the colour parameters $\Delta \mathbf{L}^{*}, \Delta \mathbf{a}^{*}$ and $\Delta \mathbf{b}^{*}$ of thermally modified aspen and grey alder wood due to solar and artificial UV irradiation for different periods of time

\begin{tabular}{|c|c|c|c|c|c|c|}
\hline \multirow[b]{3}{*}{$\begin{array}{c}\text { Exposure } \\
\text { time, } \mathbf{h}\end{array}$} & \multicolumn{3}{|c|}{ Aspen } & \multicolumn{3}{|c|}{ Grey alder } \\
\hline & $\Delta \mathbf{L}^{*}$ & $\Delta \mathbf{a}^{*}$ & $\Delta \mathbf{b}^{*}$ & $\Delta \mathbf{L}^{*}$ & $\Delta \mathbf{a}^{*}$ & $\Delta \mathbf{b}^{*}$ \\
\hline & \multicolumn{6}{|c|}{ Outdoor test } \\
\hline 2,5 & $1.5 \pm 0.3$ & $-0.7 \pm 0.0$ & $0.1 \pm 0.1$ & $1.7 \pm 0.1$ & $-0.6 \pm 0.1$ & $0.0 \pm 0.2$ \\
\hline 5 & $2.4 \pm 0.2$ & $-1.0 \pm 0.1$ & $0.2 \pm 0.1$ & $2.5 \pm 0.2$ & $-0.7 \pm 0.1$ & $0.5 \pm 0.3$ \\
\hline 10 & $3.8 \pm 0.5$ & $-1.4 \pm 0.1$ & $0.8 \pm 0.3$ & $3.9 \pm 0.3$ & $-0.9 \pm 0.1$ & $1.4 \pm 0.4$ \\
\hline \multirow[t]{2}{*}{30} & $6.0 \pm 0.7$ & $-1.0 \pm 0.1$ & $2.5 \pm 0.8$ & $6.3 \pm 0.3$ & $-0.3 \pm 0.1$ & $3.5 \pm 0.3$ \\
\hline & \multicolumn{6}{|c|}{ Indoor test } \\
\hline 2,5 & $0.5 \pm 0.2$ & $-0.6 \pm 0.3$ & $-0.6 \pm 0.3$ & $0.8 \pm 0.3$ & $-0.8 \pm 0.1$ & $-0.9 \pm 0.4$ \\
\hline 5 & $1.8 \pm 0.2$ & $-0.7 \pm 0.3$ & $-0.2 \pm 0.3$ & $1.4 \pm 0.3$ & $-0.7 \pm 0.1$ & $0.0 \pm 0.4$ \\
\hline 10 & $2.0 \pm 0.2$ & $-0.8 \pm 0.2$ & $0.0 \pm 0.1$ & $2.3 \pm 0.4$ & $-0.9 \pm 0.1$ & $0.3 \pm 0.1$ \\
\hline \multirow[t]{2}{*}{30} & $4.4 \pm 0.4$ & $-0.5 \pm 0.3$ & $2.2 \pm 0.3$ & $5.2 \pm 0.3$ & $-0.7 \pm 0.2$ & $2.8 \pm 0.6$ \\
\hline & \multicolumn{6}{|c|}{ Intense test } \\
\hline 2,5 & $-0.6 \pm 0.2$ & $-0.7 \pm 0.1$ & $-2.1 \pm 0.5$ & $-0.4 \pm 0.1$ & $-1.0 \pm 0.0$ & $-1.7 \pm 0.1$ \\
\hline 5 & $0.4 \pm 0.1$ & $-0.9 \pm 0.1$ & $-2.3 \pm 0.2$ & $0.5 \pm 0.1$ & $-1.2 \pm 0.1$ & $-1.4 \pm 0.1$ \\
\hline 10 & $0.7 \pm 0.3$ & $-1.4 \pm 0.1$ & $-2.4 \pm 0.1$ & $0.6 \pm 0.3$ & $-1.3 \pm 0.1$ & $-1.2 \pm 0.1$ \\
\hline \multirow[t]{2}{*}{30} & $4.2 \pm 0.5$ & $-1.8 \pm 0.3$ & $-1.6 \pm 0.4$ & $3.2 \pm 0.5$ & $-1.6 \pm 0.2$ & $-0.2 \pm 0.4$ \\
\hline & \multicolumn{6}{|c|}{ Mild test } \\
\hline 2,5 & $-2.2 \pm 0.2$ & $-0.7 \pm 0.1$ & $-3.1 \pm 0.3$ & $-1.2 \pm 0.2$ & $-0.6 \pm 0.1$ & $-2.1 \pm 0.2$ \\
\hline 5 & $-1.5 \pm 0.4$ & $-0.9 \pm 0.2$ & $-3.0 \pm 0.5$ & $-1.2 \pm 0.2$ & $-0.8 \pm 0.3$ & $-1.9 \pm 0.4$ \\
\hline 10 & $0.3 \pm 0.2$ & $-1.5 \pm 0.2$ & $-2.7 \pm 0.2$ & $0.3 \pm 0.1$ & $-1.3 \pm 0.2$ & $-1.8 \pm 0.2$ \\
\hline 30 & $2.4 \pm 0.3$ & $-1.6 \pm 0.2$ & $-2.4 \pm 0.5$ & $2.3 \pm 0.6$ & $-1.7 \pm 0.4$ & $-0.8 \pm 0.2$ \\
\hline
\end{tabular}




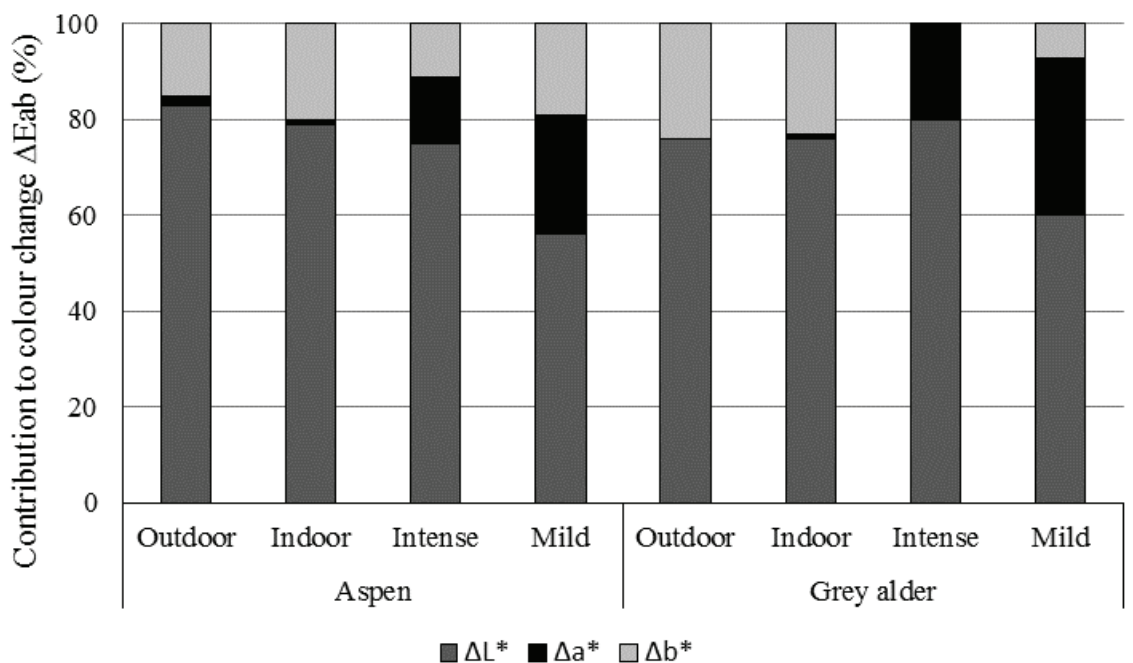

Figure 3.Contribution of the colour parameter changes $\left(\Delta \mathrm{L}^{*}, \Delta \mathrm{a}, \Delta \mathrm{b}^{*}\right)$ to the total colour change $\Delta \mathrm{Eab}$ of thermally modified aspen and grey alder wood during exposure to different irradiation conditions for $30 \mathrm{~h}$.

and artificial weathering tests was observed for the yellowness parameter $b^{*}$. In the Outdoor test, parameter $b^{*}$ values increased $\left(\Delta b^{*}>0\right)$ during the whole experiment. In the Indoor test, small decrease of the parameter $b^{*}$ was observed during initial exposure after which the parameter $b^{*}$ increased, and its values exceeded the original values $\left(\Delta b^{*}>0\right)$ after a $10 \mathrm{~h}$ exposure for aspen wood and after a $5 \mathrm{~h}$ exposure for grey alder wood. In both artificial UV irradiation tests, the initial decrease of the parameter $b^{*}$, which was significantly greater than that in the Indoor test, was observed. During the subsequent exposure, the parameter $b^{*}$ increased in both artificial irradiation tests but at the end of the experiment, the parameter $b^{*}$ values were still lower than their original ones $\left(\Delta b^{*}<0\right)$.

Figure 3 represents the effect of solar and artificial UV irradiation on the contribution of the individual colour parameters to the total colour change $\Delta \mathrm{Eab}$.
During all tests, changes in lightness parameter $\mathrm{L}^{*}$ were the major contributor to discolouration. The redness parameter a* contributed less than $2 \%$ to the total discolouration during Outdoor and Indoor tests, while significant contribution of redness parameter $a^{*}$ was detected for both artificial weathering tests with $\Delta \mathrm{a}^{*}$ value even contributing $33 \%$ in the total discolouration for grey alder wood exposed in the Mild test. Concerning contribution of chromaticity parameters $a^{*}$ and $b^{*}$ in the total discolouration, a trend was observed that changes in yellowness parameter $b^{*}$ were greater for specimens in the solar tests while changes in the redness parameter $a^{*}$ prevailed in the artificial weathering tests.

Changes in reflectance spectra at the end of the experiment, i.e. after a $30 \mathrm{~h}$ exposure, are shown in Fig. 4 in a form of difference reflectance spectra, which were calculated by subtracting the reflectance spectrum of wood after and before exposure.
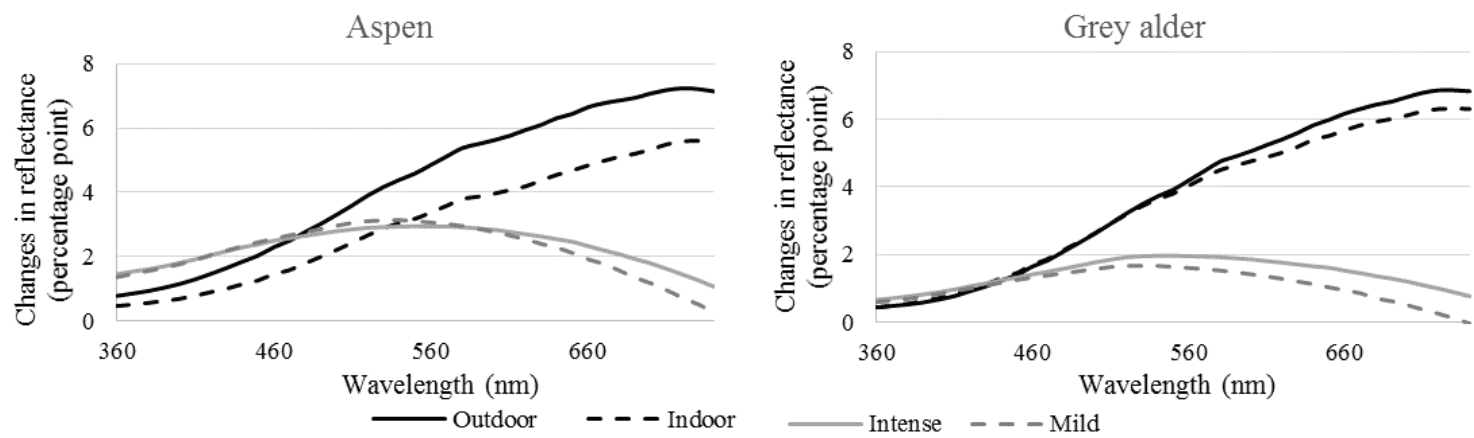

Figure 4. Difference reflectance spectra of thermally modified aspen and grey alder wood exposed to different irradiation conditions for $30 \mathrm{~h}$. 


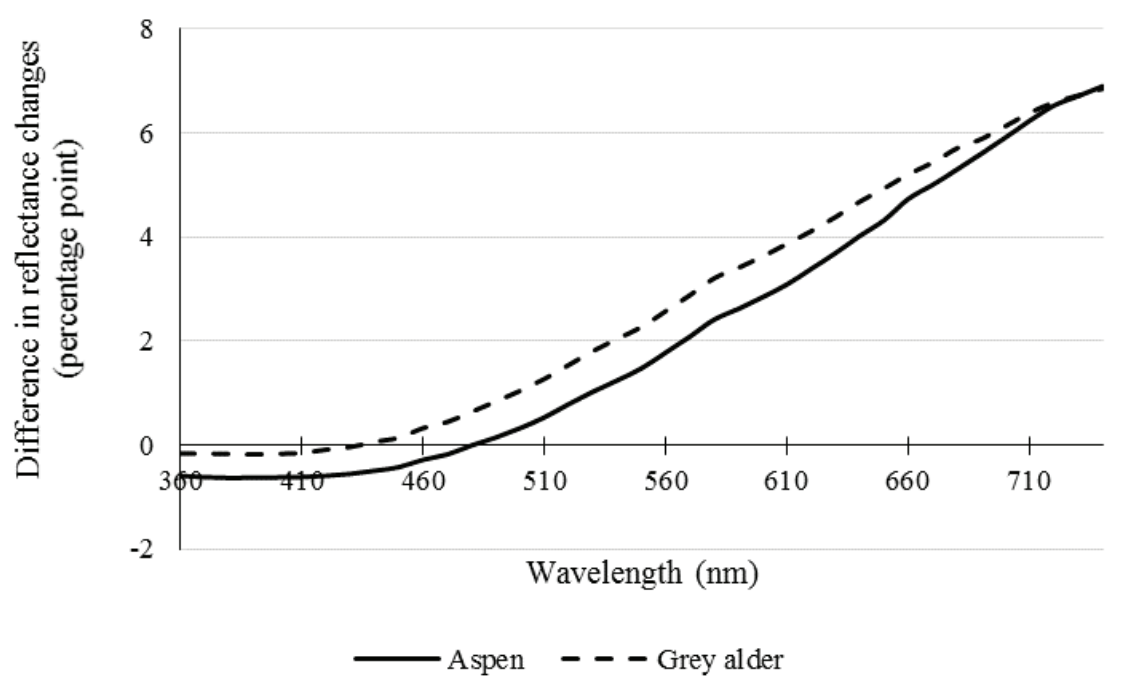

Figure 5. Difference of reflectance changes between specimens exposed to equivalent UV radiation dosages in the solar (Outdoor) and artificial UV (Mild) tests for thermally modified aspen and grey alder wood.

It can be seen that the changes in reflectance had similar trends for thermally modified wood of both species under study. For all studied irradiation conditions, reflectance increased over the whole inspected wavelength range. Only a slight increase in reflectance was detected in the shorter wavelength range for both solar and artificial irradiation. Reflectance of specimens exposed to the artificial UV irradiation changed less and quite evenly over the whole inspected wavelength range with a slight increase around $500 \mathrm{~nm}$ and hardly any changes in the wavelength range above $700 \mathrm{~nm}$. However, substantial increase of reflectance in the wavelength region above $500 \mathrm{~nm}$ was observed for specimens exposed to the solar irradiation outdoors and indoors.

To compare the effect of solar and UV radiation on changes in reflectance of thermally modified wood, the difference between changes in reflectance of Outdoor and Mild tests, during which the specimens received almost equivalent dosages of the UV radiation (Table $1)$, were calculated by subtracting the respective values (Figure 5).

It can be seen that difference between reflectance changes due to solar and artificial UV irradiation was similar for thermally modified aspen and grey alder wood. Hardly any difference was detected in the wavelength range up to $500 \mathrm{~nm}$, while substantially greater increase in reflectance was found at the longer wavelength range for specimens in the Outdoor test.

\section{Discussion}

Nevertheless, the recorded UV radiation flux density of UV radiation in the solar spectrum at midday during the Outdoor test was even higher than that used in the Intense UV test, when wood was exposed to the artificial UV irradiation of the highest intensity (Figure 1), the total UV radiation dose received by specimens in the Outdoor test was only about $60 \%$ from that received by the specimens in the Intense test. During the whole experiment, UV radiation flux density of the sunlight filtered through the window glass to which wood was exposed in the Indoor test was lower than that used in both artificial weathering tests. Moreover, the magnitude of the UV radiation dose received by the Indoor test specimens at the end of the experiment was less than that received by the specimens in the Intense UV test during the first $5 \mathrm{~h}$ of exposure. It should be mentioned that UV radiation represents only $5 \%$ from the solar radiation reaching the Earth surface (Deka et al., 2008).

As the specimens were only exposed to the irradiation for $30 \mathrm{~h}$, the substantial colour change indicates that the process of thermally modified wood discolouration is quite fast. Similar observation about very rapid discolouration in the initial period of both unmodified and thermally modified wood exposure to different light sources has been reported by several researchers (Ayadi et al. 2003; Deka et al., 2008; Oltean, Teischinger, \& Hansmann, 2008; Tolvaj \& Varga, 2012; Hauptmann et al., 2014).

It has been well documented that UV radiation causes greater or lesser discolouration in thermally modified wood. Our results suggest that the part of solar radiation (radiation above $365 \mathrm{~nm}$ ) that is not represented in the spectrum of the UVA-340 fluorescent lamps, which are widely used in the artificial weathering tests, significantly influenced the discolouration process of thermally modified wood (Figure 2). Greater discolouration was detected even 
for the specimens in the Indoor test when the total received UV radiation $(290-390 \mathrm{~nm})$ dose was $14 \%$ and $25 \%$ from that received by the specimens in the Intense and Mild tests, respectively. Besides, the discolouration of the Indoor test specimens indicate that, although the window glass absorbs part of solar radiation, the transmitted radiation can provoke substantial colour changes in thermally modified wood. These results suggest that UVA type lamps, which only imitate well the sunlight UV spectrum from $290 \mathrm{~nm}$ to $365 \mathrm{~nm}$, do not fully simulate changes induced by solar radiation in thermally modified wood. The longer wavelength range of UV radiation and the short-wavelength range of visible light are an important initiator of discolouration for thermally modified wood.

Total colour changes depend on changes in individual colour parameters. Different trends of individual colour parameter changes were observed for solar and artificial weathering tests (Table 2). However, during the time window of the experiment, the pattern of colour parameter changes was similar for both thermally modified aspen and grey alder wood. As it can be seen, changes in the individual colour parameters in the course of the experiment altered their direction. It implies that discolouration of thermally modified wood is a complicated and dynamic process with various and different chemical transformations in wood chromophores. Several researchers have reported results of thermally modified wood discolouration due to artificial weathering (Deka \& Petric 2008; Miklečić et al., 2011; Huang et al., 2012). Common trend of an increase in the lightness parameter $\mathrm{L}^{*}$ due to weathering was observed in all reported studies. However, concerning chromaticity parameters $\mathrm{a}^{*}$ and $\mathrm{b}^{*}$, different patterns have been observed. Deka \& Petric (2008) detected decrease in redness parameter $\mathrm{a}^{*}$ and increase in yellowness parameter $b^{*}$, while Huang, Kocaefe D., Kocaefe Y., Boluk \& Pichette (2012) found decrease in both parameters $\mathrm{a}^{*}$ and $\mathrm{b}^{*}$ during artificial weathering which agrees with the results established in the present study. In its turn, Miklečić, Jirouš-Rajković, Antonović \& Španić (2011) observed different trends of colour parameter changes for thermally modified ash wood depending on the thermal treatment temperature. They investigated artificial weathering of ash wood modified at $190{ }^{\circ} \mathrm{C}$ and $212{ }^{\circ} \mathrm{C}$ and observed increase in $\mathrm{a}^{*}$ and $\mathrm{b}^{*}$ for ash treated at $190{ }^{\circ} \mathrm{C}$ and increase in $\mathrm{a}^{*}$ and decrease in $\mathrm{b}^{*}$ for ash treated at $212{ }^{\circ} \mathrm{C}$. The differences in discolouration patterns may be attributed to different wood species as well as different thermal treatment conditions used in the studies.
The dissimilarity between effect of solar and artificial irradiation on thermally modified wood is well illustrated by the contribution of the individual colour parameters to the total colour change $\Delta$ Eab (Figure 3). It can be seen that for all irradiation systems changes in lightness parameter $\mathrm{L}^{*}$ contributed more than $50 \%$ to the discolouration. However, in the cases of artificial weathering, redness parameter $a^{*}$ contributed significantly to the total discolouration, while hardly any impact of changes in this parameter was detected for specimens exposed to solar irradiation.

The fact that there are differences in colour change between the specimens exposed to solar and artificial UV irradiation is also confirmed by changes in reflectance spectra in the visible light range of 360-740 nm (Figures 4 and 5). Reflectance spectra characterise wood chromophores and changes in their concentration (Pandey \& Vuorinen, 2008). The changes in reflectance clearly indicate that there are dissimilarities for various types of irradiation, while similar tendencies were observed for the specimens exposed to the irradiation of different intensities of the same type, i.e. solar or artificial UV irradiation.

The most similar UV radiation doses that specimens received during the experiment were for the Outdoor and Mild test specimens (Table 1). In the Indoor test, the UV dosage received by the specimens was much lower. Nevertheless, changes in reflectance after a $30 \mathrm{~h}$ exposure (Figure 4) are more similar for both the solar irradiation - Outdoor and Indoor tests. It implies that the UV radiation is not the dominant factor influencing thermally modified wood during exposure to solar irradiation.

Comparing the effect of radiation comprising similar UV doses but different spectral composition on changes in thermally modified wood reflectance (Figure 5), it is clearly seen that additional visible light irradiation in the Outdoor test resulted in significantly greater changes in reflectance in the wavelength range above $500 \mathrm{~nm}$. Changes in reflectance in the shorter wavelength region are quite similar for both the solar and artificial UV irradiation processes. Moreover, negative values in the short-wavelength range indicate on even slightly more changes in reflectance in this wavelength range for specimens in the Mild test than that of the Outdoor test. It indicates that the chromophores, with characteristic reflectance in the range up to $500 \mathrm{~nm}$, are relatively stable to visible light and can be altered mostly by the UV radiation. On the other hand, the markedly higher changes in the wavelength range above $500 \mathrm{~nm}$ of the specimens exposed to solar radiation suggest that thermally modified wood contains significant amount 
of chromophores which can be transformed also by the light of relatively less photons energy.

\section{Conclusions}

The colour change caused by solar and artificial UV irradiation has a similar pattern for both thermally modified hardwood species under study, namely, aspen and grey alder wood. Colour change was similar for different intensities of the same type of irradiation but differed for various irradiation types, i.e. solar or artificial UV irradiation. Noticeably greater colour changes were detected for specimens exposed to solar irradiation outdoors and indoors compared to specimens exposed to artificial UV radiation regardless the higher UV radiation doses received by the specimens during the artificial weathering. It implies that thermally modified wood contains significant amount of chromophores which can be transformed by the light of relatively less photons energy. Analyses of changes in colour parameters indicate that discolouration of thermally modified wood is a complicated and dynamic process with various and different chemical transformations in wood chromophores.

Results of the present study clearly show that the region of the solar spectrum that is not included in the spectrum of UVA-341 lamps but accounts for a substantial part of the solar radiation, namely, UV radiation of the longer wavelength range above 365 $\mathrm{nm}$ and possibly also some range of visible light, is an important initiator of chemical reactions in thermally modified wood. This suggests that UVA-340 type lamps, which only imitate well the sunlight UV spectrum from $290 \mathrm{~nm}$ to $365 \mathrm{~nm}$, do not fully imitate the changes induced by solar radiation in thermally modified wood.

\section{References}

1. Ayadi, N., Lejeune, F., Charrier, F., Charrier, B., \& Merlin, A. (2003). Color stability of heattreated wood during artificial weathering. Holz als Roh- and Werkstoff . 61, 221-226. DOI: 10.1007/s00107-003-0389-2.

2. Bächle, H., Zimmer, B., Windeisen, E., \& Wegener, G. (2010). Evaluation of thermally modified beech and spruce wood and their properties by FT-NIR Spectroscopy. Wood Science and Technology. 44, 421-433. DOI: 10.1007/s00226-010-0361-3.

3. Boonstra, M.J., Van Acker, J., Tjeerdsma, B. F., \& Kegel, E.V.(2007). Strength properties of thermally modified softwoods and its relation to polymeric structural wood constituents. Annals of Forest Science. 64(7), 679-690. DOI: 10.1051/ forest:2007048.

4. Chang, T.C., Chang, H.T., Wu, C.L., \& Chang, S.T. (2010). Influences of extractives on the photodegradation of wood. Polymer Degradation and Stability. 95, 516-521. DOI: 10.1016/S01413910(01)00039-8.

5. Deka, M., Humar, M., Rep, G., Kricej, B, Sentjurc, M., \& Petric, M. (2008). Effects of UV light irradiation on colour stability of thermally modified, copper ethanolamine treated and nonmodified wood: EPR and DRIFT spectroscopic studies. Wood Science and Technology. 42, 5-20. DOI: 10.1007/s00226-007-0147-4.

6. Deka, M. \& Petric, M. (2008). Photo-degradation of water borne acrylic coated modified and nonmodified wood during artificial light exposure. Bioresources. 3(2), 346-362.

7. Derbyshire, H. \& Miller, E.-R. (1981). The photodegradation of wood during solar irradiation. Part 1: Effects on the structural integrity of thin wood strips. Holz als Rohand Werkstoff. 39, 341-350. DOI: 10.1007/ BF02608404.

8. Esteves, B.M. \& Pereira, H.M. (2009). Wood modification by heat treatment: a review. Bioresources. 4(1), 370-404.

9. Hauptmann, M., Rosenau, T., Gindl-Altmutter, W., \& Hansmann, C. (2014). Effects of UVirradiation on tricine impregnated wood. European Journal of Wood and Wood Products. 72,617-622. DOI: 10.1007/s00107-014-0824-6.

10. Huang, X., Kocaefe, D., Kocaefe, Y., Boluk, Y., \& Pichette, A. (2012). Study of the degradation behavior of heat-treated jack pine (Pinus banksiana) under artificial sunlight irradiation. Polymer Degradation and Stability. 97, 1197-1214. DOI: 10.1016/j. polymdegradstab.2012.03.022.

11. Kishino, M., \& Nakano, T. (2004). Artificial weathering of tropical woods. Part 2: Color change. Holzforschung 58, 558-565. DOI: $10.1515 /$ HF.2004.085.

12. Miklečić, J., Jirouš-Rajković, V., Antonović, A., \& Španić, N. (2011). Discolouration of thermally modified wood during simulated indoor sunlight exposure. Bioresources. 6(1), 434-446.

13. Mitsui, K. (2006). Changes in color of spruce by repetitive treatment of light-irradiation and heat treatment. Holz als Roh- and Werkstoff. 64, 243244. DOI: $10.1007 / \mathrm{s} 00107-005-0045-0$.

14. Oltean, L., Teischinger, A., \& Hansmann, C. (2008). Wood surface discolouration due to simulated indoor sunlight exposure. Holz als 
Roh- and Werkstoff. 66, 51-56. DOI: 10.1007/ s00107-007-0201-9.

15. Pandey, K.K., \& Vuorinen, T. (2008). Comparative study of photodegradation of wood by a UV laser and a xenon light source. Polymer Degradation and Stability. 93, 2138-2146. DOI: 10.1016/j.polymdegradstab.2008.08.013.

16. Pastore, T. C.M., Santos, K.O., \& Rubim, J.C. (2004). A spectroscopic study on the effect of ultraviolet irradiation of four tropical hardwoods. Bioresource Technology International. 93, 3742. DOI: 10.1016/j.biortech.2003.10.035.

17. Sharratt, V., Hill, C. A.-S., \& Kint, D. P.R. (2009). A study of early colour change due to simulated accelerated sunlight exposure in Scots pine (Pinus sylvestris). Polymer Degradation and Stability. 94, 1589-1594. DOI: 10.1016/j. polymdegradstab.2009.04.010.

18. Srinivas, K. \& Pandey, K.K. (2012). Photodegradation of thermally modified wood. Journal of Photochemistry and Photobiology B: Biology. 117, 2012, 140-145. DOI: 10.1016/j. photobiol.2012.09.013.

19. Sudiyani, Y., Tsujiyama, S., Imamura, Y., Takahashi, M., Minato, K., \& Kajita, H. (1999).
Chemical characteristics of surfaces of hardwood and softwood deteriorated by weathering. Journal of Wood Science. 45, 348-353. DOI: 10.1007/BF00833502.

20. Temiz, A., Yildiz, U.-C., Aydin, I., Eikenes, M., Alfredsen, G., \& Colakoglu, G. (2005). Surface roughness and color characteristics of wood treated with preservatives after accelerated weathering test. Applied Surface Science. 250, 35-42. DOI: 10.1016/j.apsusc.2004.12.019.

21. Tolvaj, L., \& Mitsui, K. (2005). Light source dependance of the photodegradation of wood. Journal of Wood Science . 51, 468-473. DOI: 10.1007/s10086-004-0693-4.

22. Tolvaj, L., \& Varga, D. (2012). Photodegradtion of timber of three hardwood species caused by different light sources. Acta Silvatica et Lignaria Hungarica. 8, 145-155. DOI: 10.2478/v10303012-0012-5.

23. Williams, R.S. (2005) Weathering of wood. In R.M. Rowell (Eds.), Handbook of wood chemistry and wood composites (pp. 142185). New Yerk: CRC Press.

\section{Acknowledgements}

The authors gratefully acknowledge the financial support by the Latvian State Research Programme 'Forest and earth entrails resources: research and sustainable utilization - new products and technologies' NatProd (2014-2017). 